\title{
MicroRNA-148a inhibits breast cancer migration and invasion by directly targeting WNT-1
}

\author{
QIAN JIANG ${ }^{1}$, MIAO HE ${ }^{1}$, MENG-TAO MA ${ }^{1}$, HUI-ZHE WU ${ }^{1}$, ZHAO-JIN YU ${ }^{1}$, SHU GUAN ${ }^{2}$, \\ LONG-YANG JIANG $^{1}$, YAN WANG ${ }^{1}$, DA-DI ZHENG ${ }^{1}$, FENG JIN ${ }^{2}$ and MIN-JIE WEI ${ }^{1}$ \\ ${ }^{1}$ Department of Pharmacology, School of Pharmacy, China Medical University, Shenyang, Liaoning 110122; \\ ${ }^{2}$ Department of Surgical Oncology, The First Affiliated Hospital of China Medical University, Shenyang, Liaoning, P.R. China
}

Received September 19, 2015; Accepted October 30, 2015

DOI: $10.3892 /$ or.2015.4502

\begin{abstract}
Wnt/ $\beta$-catenin signaling pathway influences embryonic development, cell polarity and adhesion, apoptosis and tumorigenesis. MicroRNAs (miRNAs) function as important regulators of the tumorigenesis and metastasis. In the present study, we aimed to find novel targets and mechanisms of microRNA-148a (miR-148a) in regulating the migration and invasion of breast cancer cells. In the present study, miR-148a was found downregulated in human breast cancer tissues and cell lines. The ectopic miR-148a expression inhibited the migration and invasion of MCF-7 and MDA-MB-231 breast cancer cells. Furthermore, we demonstrated that WNT-1, one of the ligands of $\mathrm{Wnt} / \beta$-catenin signaling pathway, was a direct target of miR-148a. The overexpression of miR-148a reduced the mRNA and protein expression levels of WNT-1, also decreased the expression levels of the key components of Wnt $/ \beta$-catenin pathway, including $\beta$-catenin, metalloproteinase-7 (MMP-7) and T-cell factor-4 (TCF-4) in MCF-7 and MDA-MB-231 cells. In addition, the data showed that the expression of WNT-1 was significantly higher in human breast cancer tissues compared with the adjacent normal tissues and the expression of miR-148a was negatively correlated with the WNT-1 expression in human breast cancer tissues. Taken together, our results suggest that miR-148a can suppress the migration and invasion of breast cancer cells by targeting WNT-1 and inhibiting Wnt/ $\beta$-catenin signaling pathway and this will provide new insights into the molecular mechanisms of breast cancer metastasis.
\end{abstract}

Correspondence to: Professor Min-Jie Wei, Department of Pharmacology, School of Pharmacy, China Medical University, 77 Puhe Road, Shenyang North New Area, Shenyang, Liaoning 110122, P.R. China

E-mail: weiminjiecmu@163.com

Key words: miR-148a, WNT-1, breast cancer, migration, invasion, Wnt/ $\beta$-catenin signaling pathway

\section{Introduction}

Breast cancer is the most common malignant cancer and the leading cause of cancer-related death in women worldwide (1). The vast majority of breast cancer-related deaths are due to metastatic diseases (2). Breast cancer metastasis is a complex and multistep process. Numerous key pathways, such as TGF- $\beta$, WNT, NFאB, PI3K and JAK-STAT signaling pathways, are involved in breast cancer development and metastasis (3).

$\mathrm{Wnt} / \beta$-catenin pathway plays an important role in regulating cell proliferation, fate specification and differentiation in numerous developmental stages and adult tissue homeostasis. Wnt/ $\beta$-catenin pathway is activated when Wnt ligands bind to a seven-pass transmembrane Frizzled $(\mathrm{Fz})$ receptor and its co-receptor, low-density lipoprotein receptor-related protein 6 (LRP6) or its close relative LRP5. The activation of Wnt/ $\beta$-catenin pathway prevents phosphorylation and degradation of $\beta$-catenin, the main factor of this pathway, by the GSK3 $\beta$ /APC/Axin destruction complex, and increases the cytosolic and nuclear $\beta$-catenin accumulation. The $\beta$-catenin accumulated in the nucleus forms complexes with T-cell factor/lymphoid enhancing factor (TCF/LEF) transcription factors and consequently activates target genes regulating cell proliferation, apoptosis and migration $(4,5)$. Wnt/ $\beta$-catenin pathway has been reported to be abnormally activated in a variety of cancers including breast cancer (6-8).

MicroRNAs (miRNAs) are small endogenous non-coding RNAs that post-transcriptionally regulate gene expression through mRNA degradation or translational repression and monitor several biological processes (9). In general, individual miRNAs regulate multiple mRNAs and individual mRNAs can be targeted by multiple miRNAs (9). Several human miRNAs have been shown to regulate the metastasis of breast cancer cells $(10,11)$. MicroRNA-148a (miR-148a), as a member of miR-148/152 family, plays an important role in the growth and development of normal tissues and is involved in the genesis and development of disease (12). The downregulated expression of miR-148a has been found in human gastrointestinal (13)and pancreatic cancers $(14,15)$, and other tumor types (16). Recent studies have shown that miR-148a is downregulated in breast cancer cells and tumors $(17,18)$. However, the roles and mechanisms of miR-148a in breast cancer metastasis remain to be elucidated. 
In the present study, we found downregulated expression of miR-148a in breast cancer tissues and cell lines. Furthermore, we demonstrated that miR-148a was able to inhibit the migration and invasion of breast cancer cells by transfecting miR-148a mimic in MCF-7 and MDA-MB-231 cells. Importantly, our results showed miR-148a directly inhibited the expression of WNT-1 and inactivated the Wnt/ $\beta$ catenin pathway in breast cancer cells. These findings provide new insights into the molecular mechanisms of breast cancer metastasis and provide a therapeutic strategy for the treatment of cancer breast.

\section{Materials and methods}

Cell lines. Human embryonic kidney cell line 293T, breast cancer cell lines (MCF-7, MDA-MB-231, SKBR3, T47D, BT549 and MDA-MB-435S), and mammary epithelial cell (MCF-10A) were all purchased from American Type Culture Collection (ATCC; Manassas, VA, USA). The cells were cultured in a humidified atmosphere with $5 \% \mathrm{CO}_{2}$ at $37^{\circ} \mathrm{C}$.

Cell transfection. The miR-148a mimic and negative control (NC) mimic were purchased from RiboBio (Guangzhou, China). MCF-7 and MDA-MB-231 cells were seeded on 6 -well plates $\left(3 \times 10^{5} /\right.$ well $)$, and cultured overnight. Cells were then transfected with $15 \mathrm{nM}$ miR-100 mimic or miR-NC using Lipofectamine 2000 according to the manufacturerss instructions (Life Technologies, USA). After $48 \mathrm{~h}$, the cells were used for western blotting and qRT-PCR analysis.

RNA isolation and $q R T-P C R$ analysis. Total RNA and miRNAs from breast cancer cells were isolated using a miRNA isolation kit (BioTeke, China). qRT-PCR for miR-148a was performed using the TaqMan MicroRNA assay as described in our previous studies (19). For mRNA, $100 \mathrm{ng}$ RNA was reverse transcribed to cDNA using M-MLV reverse transcriptase (Promega, USA), followed by qPCR using SYBR Premix Ex Taq ${ }^{\mathrm{TM}}$ II kit (Takara, Japan) as described in our previous studies (19). The expression levels of miR-148a and WNT-1, TCF-4, LEF-1 mRNA were normalized to that of U6 small nuclear RNA (U6 snRNA) or GAPDH gene. The PCR amplification primer sequences are shown in Table I. The fold-change for each miRNA and mRNA relative to the control was calculated using the $2^{-\Delta \Delta \mathrm{Ct}}$ method.

Western blot analysis. Cells were lysed and total proteins were extracted as previously described (19). Equal amounts of proteins $(30-50 \mu \mathrm{g})$ were subjected to $10 \%$ SDS-PADE separation, and then transferred to PVDF membranes. Membranes were incubated with primary antibodies against human WNT-1 (1:400; Boster), $\beta$-catenin (1:1,000; PeproTech), MMP-7 (1:500; Boster) or GAPDH $(1: 1,000)$ followed by incubation with peroxidase-conjugated secondary antibody (Santa Cruz Biotechnology, USA). Protein bands were visualized by enhanced chemiluminescence (ECL; Amersham, Germany). The expression levels of proteins were quantitatively analyzed with FluorChem V2.0 software (Alpha Innotech Corp., USA).

Dual luciferase reporter assay. 293T cells $\left(1.2 \times 10^{4}\right)$ in 24-well plates were co-transfected with $15 \mathrm{nM}$ of miR-148a
Table I. Primer sequences used for the qRT-PCR analysis.

\begin{tabular}{lcl}
\hline Application & $\begin{array}{c}\text { Oligo- } \\
\text { nudeotides }\end{array}$ & \multicolumn{1}{c}{ Sequences (5'-3') } \\
\hline miR-148a & F & GGCAGTCTCAGTGCACTACAG \\
& R & GTGCAGGGTCCGAGGT \\
U6 & F & CTCGCTTCGGCAGCACA \\
& R & AACGCTTCACGAATTGCGT \\
WNT-1 & F & TGCACGCACACGCGCGTACTGCAC \\
& R & CAGGATGGCAAGAGGGTTCATG \\
TCF-4 & F & GCAATGTGGCAACTTGGAC \\
& R & CAGACCAAGCTCCTGATCCT \\
GAPDH & F & AGCCACATCGCTCAGACAC \\
& R & GCCCAATACGACCAAATCC
\end{tabular}

F, forward; $R$, reverse.

mimic or miR-NC and $10 \mathrm{ng}$ of luciferase reporter plasmids containing either wild-type or mutant WNT-1-3'-UTR using Lipofectamine 2000. Forty-eight hours after transfection, luciferase reporter assays were performed using the Dual Luciferase Reporter Assay kit (Promega), according to the manufacturer's protocol.

Transwell migration and invasion assays. The migration and invasion of cells were analyzed using 24-well Boyden chambers with $8-\mu \mathrm{m}$ pore size polyethylene membranes (Corning, USA). For the invasion assay, the Transwell membranes were precoated with Matrigel (BD Biosciences, USA). For both assays, cells were seeded in starvation medium on the top chamber, and the bottom chamber was filled with $0.5 \mathrm{ml}$ cell culture medium containing $10 \%$ FBS. After $24 \mathrm{~h}$ incubation, the cells that migrated or invaded to the lower chamber were fixed with $4 \%$ paraformaldehyde and stained with crystal violet solution. The cells were counted under a light microscope (magnification, x200; five random fields/well), and were analyzed using ImageJ software.

Human samples. Human breast cancer and adjacent normal tissues for qRT-PCR analysis were obtained from 69 breast cancer patients and for in situ hybridization and immunohistochemistry were obtained from 55 breast cancer patients, who underwent surgery at the First Affiliated Hospital of China Medical University between 2011 and 2012. Written informed consent was obtained from all patients. The study was approved by the Institutional Review Board of China Medical University Research Ethics Committee. This research was conducted in accordance with the Declaration of Helsinki.

Immunohistochemistry. Immunohistochemistry was performed as previously described (20). Briefly, 4- $\mu \mathrm{m}$ sections obtained from paraffin-embedded tumor tissues from breast cancer patients were incubated with primary antibody against WNT-1 (1:200; Boster). Images from each section were evaluated under a Nikon Eclipse 80i microscope (at a magnification of x200; Nikon, Japan). Five random fields without overlaps 
A

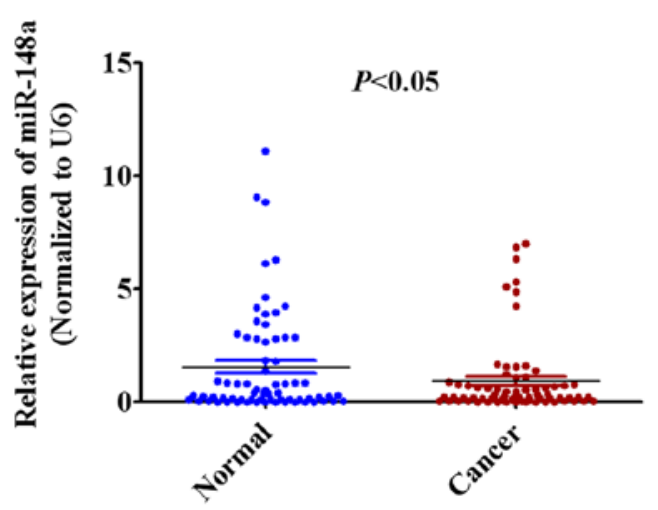

C

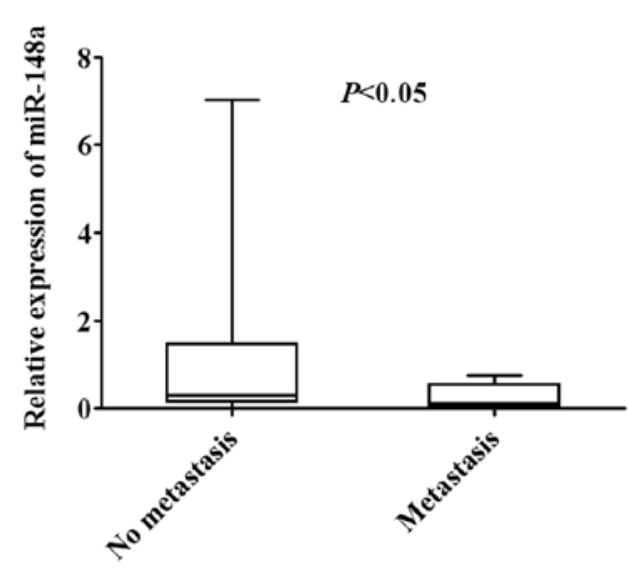

$\mathrm{B}$

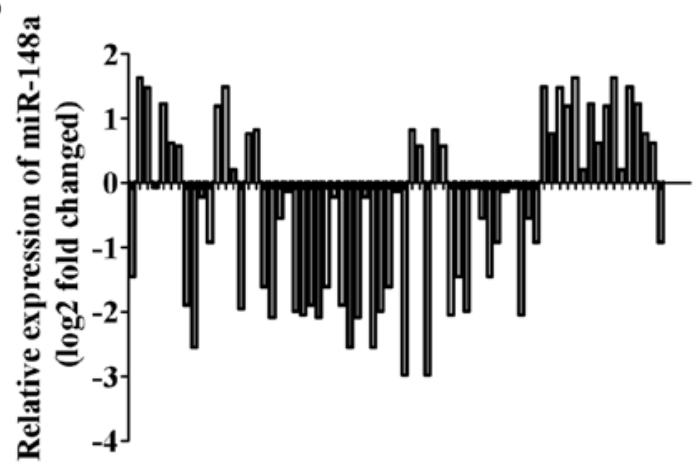

$\mathrm{D}$

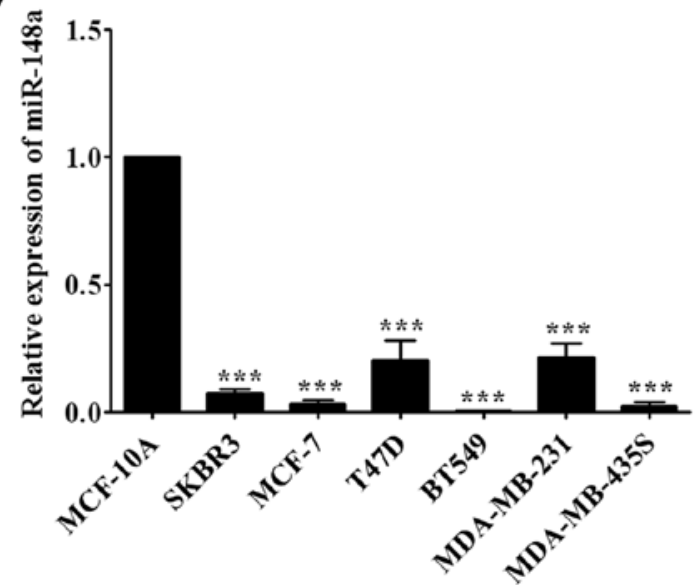

Figure 1. miR-148a expression is downregulated in breast cancer tissues and cell lines. (A) miR-148a expression in 69 pairs of human breast cancer tissues (cancer) and adjacent normal tissue (normal) by qRT-PCR. The expression was normalized to the level of U6 in each sample. (B) Fold-changes of miR-148a of each individual paired sample. The data are presented as $\log 2$ fold-change (cancer/normal). (C) The low expression of miR-148a was correlated with lymph node metastasis in 69 cases of human breast cancer tissues by Mann-Whitney U test. (D) miR-148a expression in human mammary epithelial MCF-10A cells, breast cancer SKBR3, MCF-7, T47D, BT549, MDA-MB-231 and MDA-MB-435S cells was measured by qRT-PCR. Data are presented as mean \pm SD from there independent experiments. ${ }^{* * *} \mathrm{P}<0.0001$ vs. MCF-10A.

from each section were counted. The intensity score was defined as: for no staining (0), weak (1), moderate (2) or strong (3) staining. The percentage score was defined as 0 for $<5 \%$ staining, 1 for $5-25 \%$ staining, 2 for $26-50 \%$ staining, 3 for $51-75 \%$ staining, and 4 for $>75 \%$ staining. The intensity scores were multiplied with the percentage score to obtain the final scores.

In situ hybridization. In situ hybridization was performed using Enhanced Sensitive ISH Detection KitII as specified by the manufacturer (MK1030; Boster, China). Briefly, the slides were hybridized with $8 \mu \mathrm{g} / \mathrm{ml}$ probe complementary to miR-148a LNA-modified and DIG-labeled (Shanghai Sangon Biological Engineering Technology And Service Co., Ltd., China). After incubation with anti-DIG-HRP Fab fragments conjugated to horseradish peroxidase, the slides were detected by incubating with 3,3'-diaminobenzidine (DAB) and nuclei were counterstained with hematoxylin. Quantification of the staining intensity of miR-148a was performed through image analysis the same manner as immunohistochemistry.

Statistical analysis. Analyses were performed using SPSS 17.0. A two-tailed Student's t-test was used to evaluate the statistical significance of the differences between two groups. One-way analysis of variance (ANOVA) was used to compare the differences among three or more groups. The Pearson's rank correlation analysis was applied to assess the association between the expression of miR-148a and WNT-1. Probability values $<0.05$ were considered to indicate a statistically significant result.

\section{Results}

Expression of miR-148a is downregulated in breast cancer tissues and cell lines. We measured miR-148a expression in 69 pairs of human breast cancer tissues and adjacent normal breast tissues by qRT-PCR to observe the clinical relevance of miR-148a in human breast cancer patients. The findings showed that the expression of miR-148a in human breast cancer tissues was significantly lower than in the adjacent normal breast tissues (Fig. $1 \mathrm{~A} ; \mathrm{P}<0.05)$. In addition, we found that miR-148a expression was decreased at least 2-fold compared with adjacent normal breast tissues in $15.9 \%(11 / 69)$ of human breast cancer cases (Fig. 1B). Furthermore, the low expression of miR-148a was shown to be closely correlated with lymph node metastasis by Mann-Whitney $\mathrm{U}$ test $(\mathrm{P}<0.05$; Fig. 1C). We also found that the expression of miR-148a was significantly downregulated in SKBR3, MCF-7, T47D, BT549, 
A
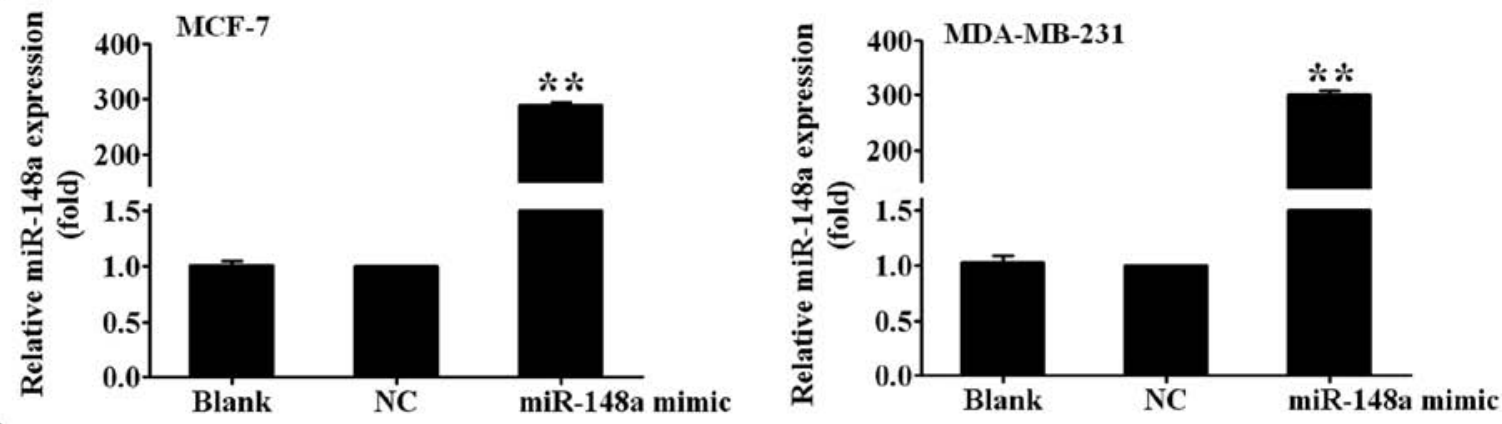

B
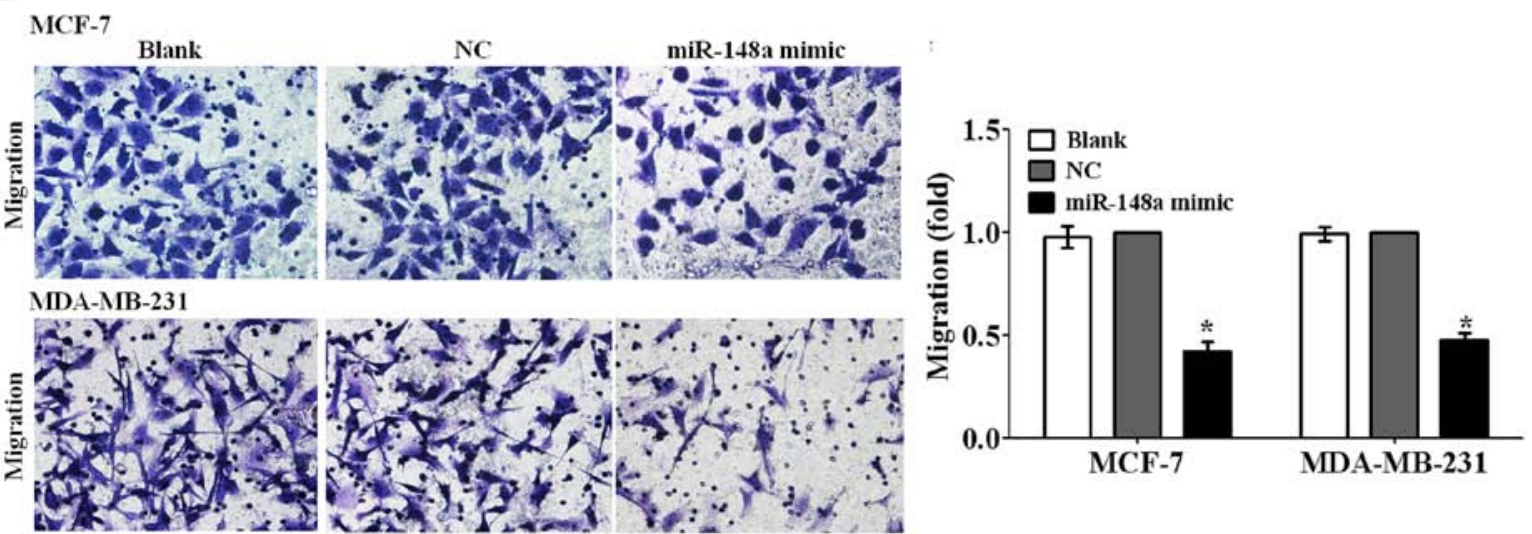

$\mathrm{C}$
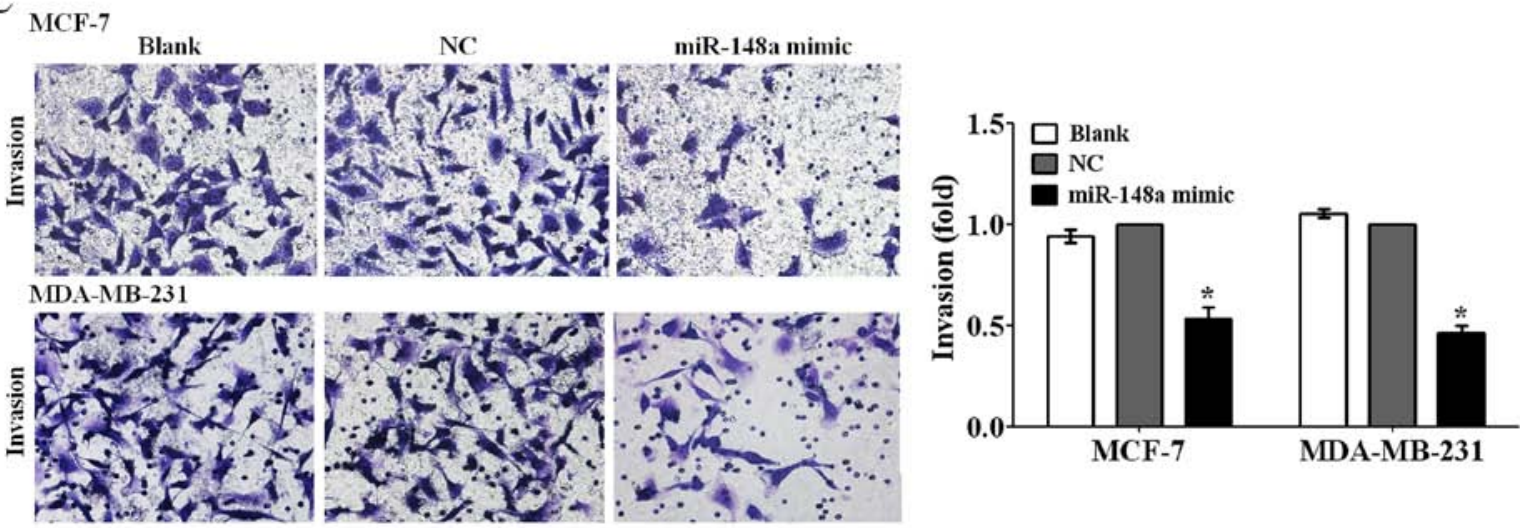

Figure 2. miR-148a suppresses the migration and invasion of breast cancer cells. (A) The relative expression of miR-148a was detected by qRT-PCR at $48 \mathrm{~h}$ after transfection with miR-148a mimic or NC in MCF-7 and MDA-MB-231 breast cancer cells. (B) The cell migration and (C) invasion abilities were measured by Transwell migration and invasion assays after transfection with miR-148a mimic or NC in MCF-7 and MDA-MB-231 cells. Cells migrating and invading the lower Transwell chambers were counted (magnification, $\mathrm{x} 200$ ). The cell number migrating and invading the lower chambers in NC group was set as 1 . Data are presented as mean $\pm \mathrm{SD}$ from there independent experiments. ${ }^{*} \mathrm{P}<0.05,{ }^{* * *} \mathrm{P}<0.01$ vs. NC group.

MDA-MB-231 and MDA-MB-435S breast cancer cells compared with human mammary epithelial MCF-10A cells by qRT-PCR analysis (Fig. 1D). Overall, these results suggested that the expression of miR-148a was downregulated in breast cancer tissues and established cell lines, and the low expression of miR-148a may be relevant to metastasis of breast cancer.

Ectopic miR-148a expression inhibits the migration and invasion of breast cancer cells. To observe whether miR-148a can inhibit the migration and invasion of breast cancer cells, we first transfected MCF-7 and MDA-MB-231 breast cancer cells with miR-148a mimic for $48 \mathrm{~h}$, and then detected the expression levels of miR-148a using qRT-PCR analysis. It is noteworthy that the expression of miR-148a was increased by 280- and 300-fold, respectivly, in MCF-7 and MDA-MB-231 cells transfected with the miR-148a mimic relative to those transfected with $\mathrm{NC}(\mathrm{P}<0.01$; Fig. $2 \mathrm{~A})$. We measured the changes of migration and invasive abilities of MCF-7 and MDA-MB-231 cells transfected with the miR-148a mimic by Transwell migration and invasion assays. The results showed that the overexpression of miR-148a suppressed the migration ability of MCF-7 and MDA-MB-231 cells to 40 and $45 \%$ of the control $(\mathrm{P}<0.05$; Fig. $2 \mathrm{~B})$, and decreased the invasion abilities of MCF-7 and MDA-MB-231 cells to 50 and $45 \%$ of the control $(\mathrm{P}<0.05$; Fig. 2C). The data suggested that miR-148a inhibited breast cancer cell migration and invasion.

WNT-1 is a direct target of miR-148a. To ascertain the possible mechanisms of miR-148a suppressing the migration and invasion of breast cancer cells, we predicted the putative targets 


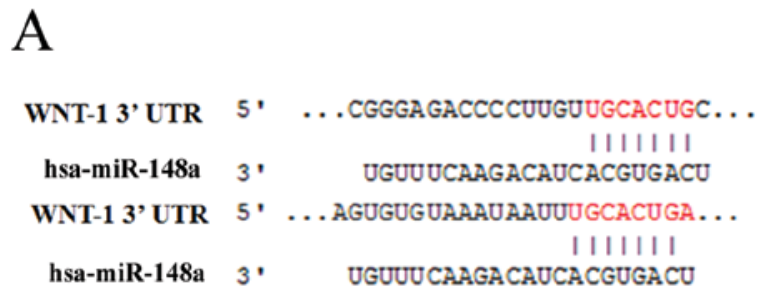

$\mathrm{B}$

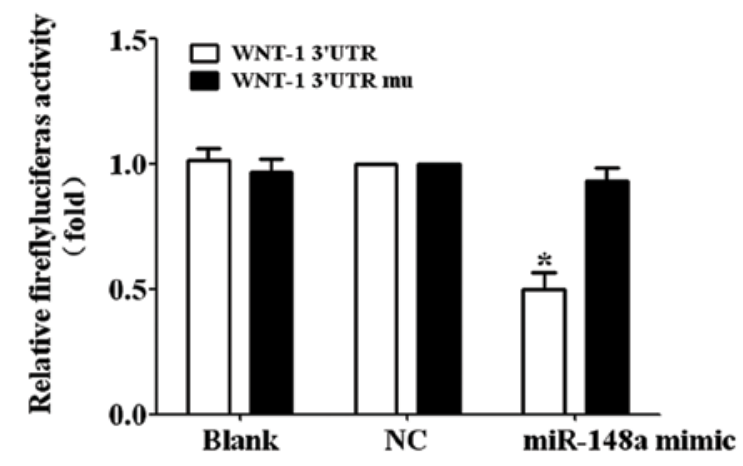

$\mathrm{C}$

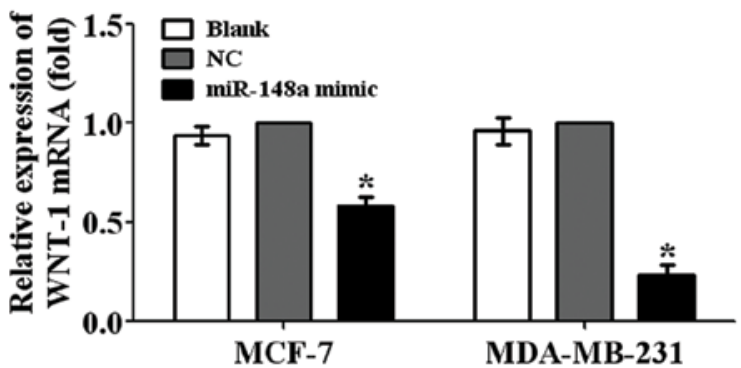

$\mathrm{D}$

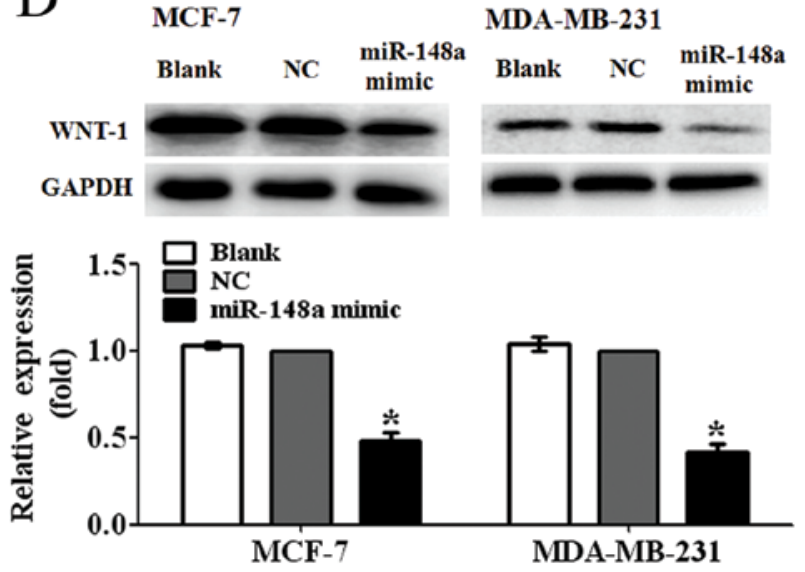

Figure 3. WNT-1 is a direct target of miR-148a in breast cancer cells. (A) Schematics of two highly conserved miR-148a binding sites in human WNT-1-3'UTR. (B) Luciferase reporter assay in 293T cells co-transfected with miR-148a mimic or NC and PGL3-WNT-1-3'UTR or PGL3-WNT-1-3'UTR mu. Relative luciferase activity was measured at $48 \mathrm{~h}$ after transfection. (C) The relative expression of WNT-1 was detected by qRT-PCR at $48 \mathrm{~h}$ after transfection with miR-148a mimic or NC in MCF-7 and MDA-MB-231 cells. (D) Representative western blotting images and the relative WNT-1 protein expression was analyzed with GAPDH as an internal control at $48 \mathrm{~h}$ after transfection with miR-148a mimic or NC in MCF-7 and MDA-MB-231 cells. Data are presented as mean \pm SD from there independent experiments. ${ }^{*} \mathrm{P}<0.05$ vs. NC group.

of miR-148a by TargetScan. We focused on the genes related to Wnt/ $\beta$-catenin signaling pathway involved in the tumor metastasis. We found that WNT-1, one of the major ligands of Wnt/ $\beta$-catenin signaling pathway, was one of the targets of miR-148a (Fig. 3A). To further test whether WNT-1 was a direct target of miR-148a, we constructed a luciferase reporter plasmid containing WNT-1 3'-untranslated region (3'-UTR) harboring a conserved miR-148a binding site (pGL3-WNT-1-3'UTR) and a plasmid containing WNT-1-3'-UTR with miR-148a target sequences mutated (pGL3-WNT-1-3'UTR mu). The pGL3WNT-1-3'UTR or pGL3-WNT-1-3'UTR mu was cotransfected with the miR-148a mimic or NC into $293 \mathrm{~T}$ cells. The reporter assay showed that miR-148a mimic significantly decreased the luciferase activity by $\sim 50 \%$ in $293 \mathrm{~T}$ cells co-transfected with the pGL3-WNT-1-3'UTR. However, the luciferase activity in the cells co-transfected with the pGL3-WNT-1-3'UTR mu was not significantly reduced $(\mathrm{P}<0.05$; Fig. $3 \mathrm{~B})$. These findings suggested that WNT-1 was a direct target of miR-148a.

Next, we found that the ectopic miR-148a expression decreased the WNT-1 mRNA expression levels to $\sim 55$ and $25 \%$ of the NC in MCF-7 and MDA-MB-231 cells $(\mathrm{P}<0.05$, Fig. 2C). Furthermore, the protein expression levels in the MCF-7 and MDA-MB-231 cells transfected with miR-148a mimic were found suppressed to 50 and $40 \%$ of the control, respectively $(\mathrm{P}<0.05$; Fig. $2 \mathrm{D})$. These data demonstrated that miR-148a was able to inhibit the expression of WNT-1 in breast cancer cells.
Overexpression of miR-148a inhibits the activation of Wnt/ $\beta$-catenin signaling pathway. WNT-1 is an important ligand of $\mathrm{Wnt} / \beta$-catenin pathway. To further investigate whether miR-148a can inhibit the activation of $\mathrm{Wnt} / \beta$-catenin pathway by targeting WNT-1 in breast cancer cells, we detected the protein expression levels of $\beta$-catenin, a central component of Wnt/ $\beta$-catenin pathway, and MMP-7, a major target gene of Wnt/ $\beta$-catenin pathway related to metastasis, in MCF-7 and MDA-MB-231 cells transfected with miR-148a mimic. We observed that the overexpression of miR-148a significantly reduced the protein expression levels of $\beta$-catenin and MMP-7 in MCF-7 and MDA-MB-231 cells, compared with NC-transfected cells (Fig 4A; $\mathrm{P}<0.05$ ). In addition, the results also showed that the ectopic miR-148a expression obviously decreased the mRNA expression levels of $\mathrm{T}$ cell factor-4 (TCF-4), one of the important transcription factors of Wnt/ $\beta$-catenin pathway, in MCF-7 and MDA-MB-231 cells (Fig. 4B; $\mathrm{P}<0.05$ ). Taken together, the findings suggested that miR-148a could suppress the migration and invasion of breast cancer cells by targeting WNT-1 and inhibiting the activation of $\mathrm{Wnt} / \beta$-catenin signaling pathway.

miR-148a expression is negatively correlated with the expression of WNT-1 in human breast cancer tissues. To further evaluate the relevance of the endogenous expression of miR-148a and WNT-1, we measured the expression of miR-148a using in situ hybridization and the expression 

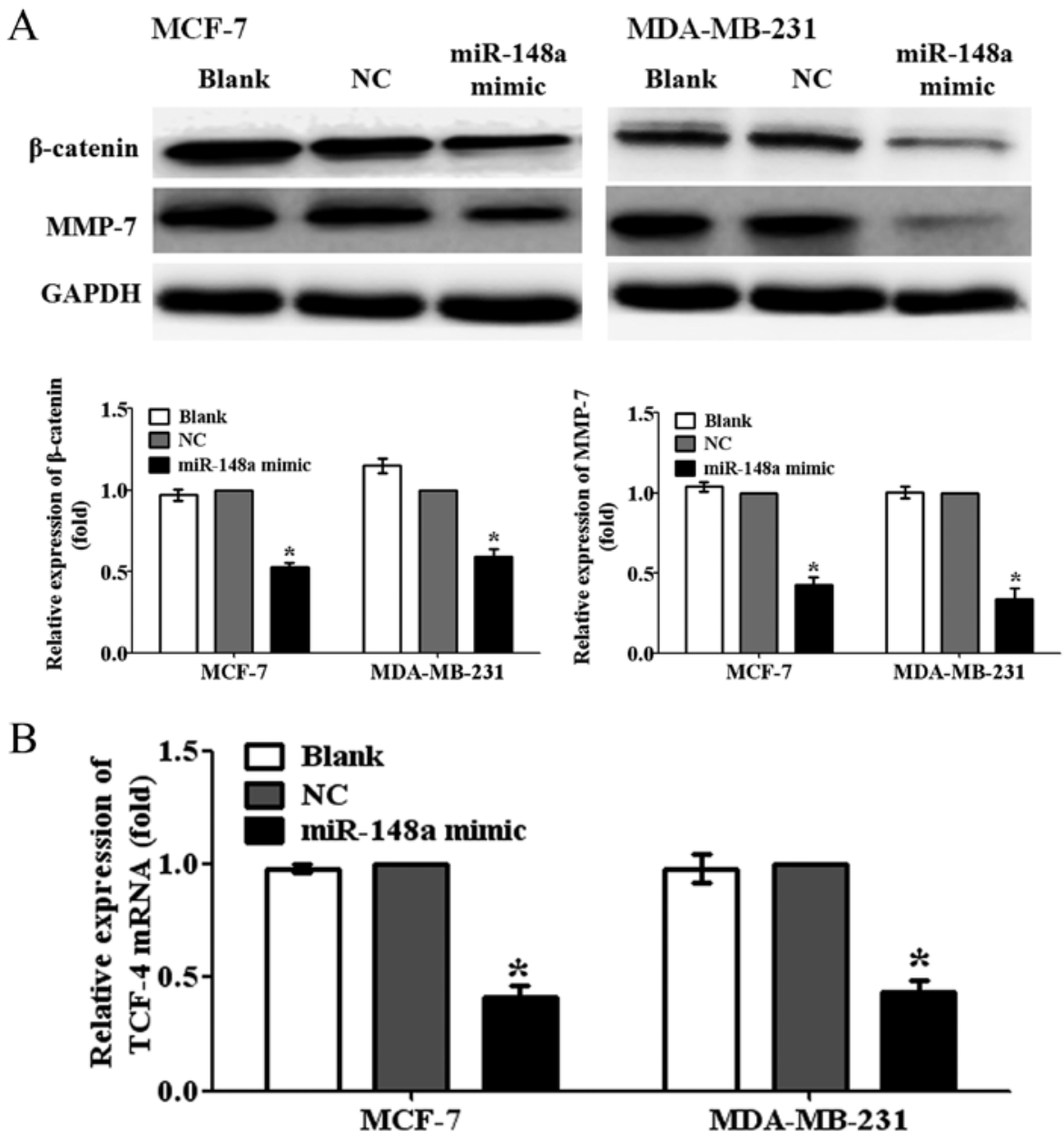

Figure 4. Ectopic miR-148a expression inhibits the activation of Wnt/ $\beta$-catenin signaling pathway. (A) Representative western blot images and the relative protein expression levels of $\beta$-catetin and MMP-7 were analyzed with GAPDH as an internal control at $48 \mathrm{~h}$ after transfection with miR-148a mimic or NC in MCF-7 and MDA-MB-231 cells. (B) The relative mRNA expression levels of TCF-4 was detected by qRT-PCR at $48 \mathrm{~h}$ after transfection with miR-148a mimic or NC in MCF-7 and MDA-MB-231 cells. Data are presented as mean \pm SD from there independent experiments. * $\mathrm{P}<0.05$ vs. NC group.

of WNT-1 protein by immunohistochemistry in 55 pairs of human breast cancer tissues and adjacent normal tissues with tissue microarray (TMA). As shown in Fig. 5A and B, the expression of WNT-1 was significantly higher in human breast cancer tissues compared with the adjacent normal tissues $(\mathrm{P}<0.0001)$. Pearson rank correlation analysis showed that the expression of miR-148a was inversely related to the expression of WNT-1 protein in breast cancer tissues (Fig. 5C; $\mathrm{P}<0.01)$.

\section{Discussion}

Wnt/ $\beta$-catenin signaling pathway influences embryonic development, cell polarity and adhesion, apoptosis and tumorigenesis $(21,22)$. It is known that $\mathrm{Wnt} / \beta$-catenin pathway is upregulated in breast cancer (6) and other types of tumors (8). WNT-1 was the original Wnt identified as an oncogene in mouse mammary tumors (23). Wong et al reported that there was a higher positive expression rate in human breast tumors (24). In our study, we also found that the WNT-1 was obviously upregulated in human breast cancer tissues when compared with the adjacent normal tissues. Wnt/ $\beta$-catenin pathway has been shown to be involved in the tumor develop- ment and metastasis (5). Targeting the Wnt/ $\beta$-catenin pathway would be very important to inhibit the metastasis of breast cancer.

miRNAs function as regulators of many oncobiological processes, such as tumorigenesis and metastasis (9). It has been demonstrated that many miRNAs can target and inhibit the main factors of WNT/B-catenin pathway and regulate the biological function of cancer cells. Wen et al reported that miR-126 suppressed papillary thyroid carcinoma cell proliferation and migration by directly repressing the expression of LRP6, a major regulator of the Wnt/ $\beta$-catenin signaling cascade (25). miR-577 was found to directly target the Wnt/ $\beta$-catenin pathway components LRP6 and $\beta$-catenin, and inhibit glioblastoma multiforme growth (26). Subramanian et al found that miR-29b decreased the transactivation of $\beta$-catenin target genes in human colorectal cancer cells (27).

In the present study, we found that miR-148a could inhibit the migration and invasion of breast cancer cells by directly targeting WNT-1 and inhibiting the activation of Wnt/ $\beta$-catenin pathway. Furthermore, we also demonstrated that the expression of miR-148a was inversely related to the expression of WNT-1 in breast cancer tissues. Similarly, Yan et al also reported that WNT-1 was a target gene of 
A
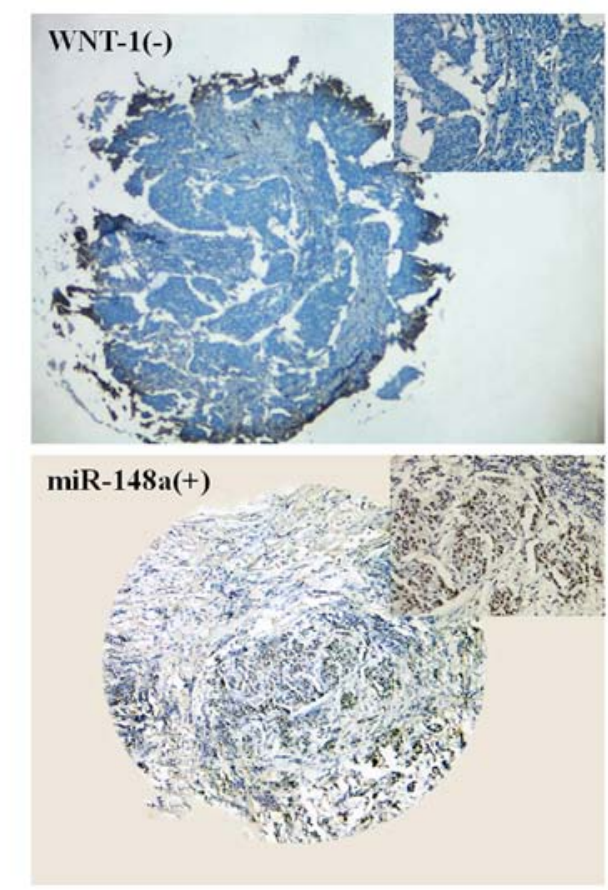

B

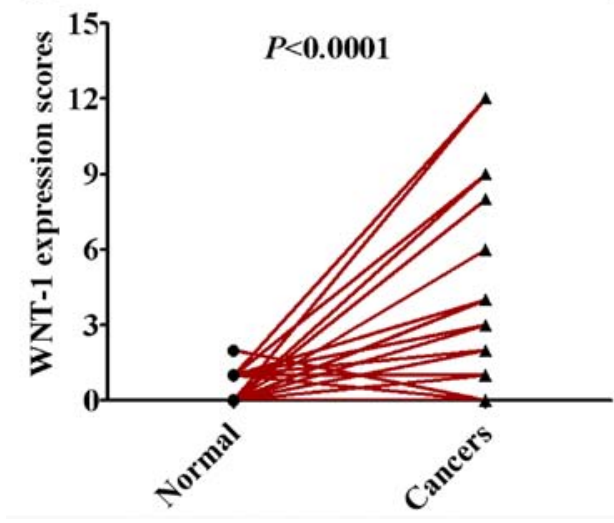

$\mathrm{C}$

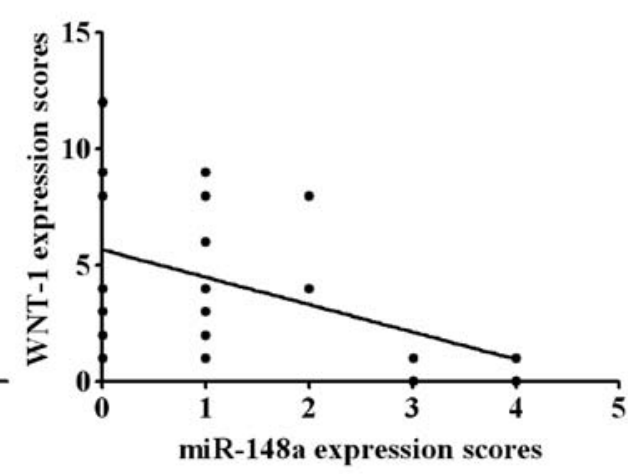

Figure 5. The expression of miR-148a is negatively correlated with the expression of WNT-1 in human breast cancer tissues. (A) Representative images of miR-148a expression measured by in situ hybridization and WNT-1 expression measured by immunohistochemistry in 55 pairs of human breast cancer tissues (cancer) and adjacent normal tissues (normal) with tissue microarray (TMA). (B) The expression of WNT-1 in 55 pairs of human breast cancer tissues and adjacent normal tissues. (C) Correlation analysis showed that the miR-148a expression was negatively related to the expression of WNT-1 in breast cancer tissues.

miR-148a in hepatocellular carcinoma cells (28). In addition, Joshi et al found that miR-148a reduced lung tumorigenesis in vitro and in vivo through the downmodulation of matrix metalloproteinase 15 (MMP15) and Rho-associated kinase 1 (ROCK1) (29). miR-148a was also demonstrated as a prognostic oncomiR to target mitogen-inducible gene 6 (MIG6) and BIM, and regulate EGFR and apoptosis in glioblastoma (30). Obviously, miR-148a plays different roles either as an oncomiR or as an antimiR in the tumor cells of different types by directly targeting different target genes.

In conclusion, our studies suggest that miR-148a can inhibit the migration and invasion of breast cancer cells by directly targeting WNT-1 and downregulating the Wnt/ $\beta$ catenin signaling pathway. This will provide a new strategy for treating metastasis of breast cancer. However, the complex regulatory network of miR-148a in regulating the migration and invasion of breast cancer should be further explored.

\section{Acknowledgements}

The present study was supported by grants from the National Natural Science Foundation of China (grant no. 81373427), the Program for Liaoning Innovative Research Team in University, LNIRT, China (grant no. LT2014016), the Liaoning Provincial Science and Technology Program, China (grant no. 2014021085), the Program for Liaoning Excellent Talents in University, China (grant no. LJQ2014084), and the S\&T Projects in Shenyang, China (grant no. F14-232-6-05).

\section{References}

1. Donepudi MS, Kondapalli K, Amos SJ and Venkanteshan P: Breast cancer statistics and markers. J Cancer Res Ther 10: 506-511, 2014.

2. Gangadhara S, Barrett-Lee P, Nicholson RI and Hiscox S: Pro-metastatic tumor-stroma interactions in breast cancer. Future Oncol 8: 1427-1442, 2012. 
3. Fazilaty $\mathrm{H}$ and Mehdipour P: Genetics of breast cancer bone metastasis: A sequential multistep pattern. Clin Exp Metastasis 31: 595-612, 2014.

4. Clevers H: Wnt/beta-catenin signaling in development and disease. Cell 127: 469-480, 2006.

5. MacDonald BT, Tamai K and He X: Wnt/beta-catenin signaling: Components, mechanisms, and diseases. Dev Cell 17: 9-26, 2009.

6. Khramtsov AI, Khramtsova GF, Tretiakova M, Huo DZ, Olopade OI and Goss KH: Wnt/beta-catenin pathway activation is enriched in basal-like breast cancers and predicts poor outcome. Am J Pathol 176: 2911-2920, 2010.

7. Arend RC,Londono-Joshi AI, Straughn JM Jr and Buchsbaum DJ: The Wnt/beta-catenin pathway in ovarian cancer: A review. Gynecol Oncol 131: 772-779, 2013.

8. Serafino A, Moroni N, Zonfrillo M, Andreola F, Mercuri L, Nicotera G, Nunziata J, Ricci R, Antinori A, Rasi G, et al: WNT-pathway components as predictive markers useful for diagnosis, prevention and therapy in inflammatory bowel disease and sporadic colorectal cancer. Oncotarget 5: 978-992, 2014.

9. Bartel DP: MicroRNAs: Genomics, biogenesis, mechanism, and function. Cell 116: 281-297, 2004.

10. Liu P, Tang H, Chen B, He Z, Deng M, Wu M, Liu X, Yang L, Ye $\mathrm{F}$ and $\mathrm{Xie} \mathrm{X}$ : miR-26a suppresses tumour proliferation and metastasis by targeting metadherin in triple negative breast cancer. Cancer Lett 357: 384-392, 2015.

11. Chan SH, Huang WC, Chang JW, Chang KJ, Kuo WH, Wang MY, Lin KY, Uen YH, Hou MF, Lin CM, et al: MicroRNA-149 targets GIT1 to suppress integrin signaling and breast cancer metastasis. Oncogene 33: 4496-4507, 2014.

12. Chen Y, Song YX and Wang ZN: The microRNA-148/152 family: Multi-faceted players. Mol Cancer 12: 43, 2013.

13. Chen Y, Song Y, Wang Z, Yue Z, Xu H, Xing C and Liu Z: Altered expression of miR-148a and miR-152 in gastrointestinal cancers and its clinical significance. J Gastrointest Surg 14: 1170-1179, 2010.

14. Zhang R, Li M,Zang W, Chen X, Wang Y, Li P, Du Y, Zhao G and $\mathrm{Li}$ L: MiR-148a regulates the growth and apoptosis in pancreatic cancer by targeting CCKBR and Bcl-2. Tumour Biol 35: 837-844, 2014.

15. Liffers ST, Munding JB, Vogt M, Kuhlmann JD, Verdoodt B Nambiar S, Maghnouj A, Mirmohammadsadegh A, Hahn SA and Tannapfel A: MicroRNA-148a is down-regulated in human pancreatic ductal adenocarcinomas and regulates cell survival by targeting CDC25B. Lab Invest 91: 1472-1479, 2011.

16. Magrelli A, Azzalin G, Salvatore M, Viganotti M, Tosto F Colombo T, Devito R, Di Masi A, Antoccia A, Lorenzetti S, et al: Altered microRNA expression patterns in hepatoblastoma patients. Transl Oncol 2: 157-163, 2009.

17. Xu Q, Jiang Y, Yin Y, Li Q, He J, Jing Y, Qi YT, Xu Q, Li W, $\mathrm{Lu} \mathrm{B}$, et al: A regulatory circuit of miR-148a/152 and DNMT1 in modulating cell transformation and tumor angiogenesis through IGF-IR and IRS1. J Mol Cell Biol 5: 3-13, 2013.
18. Yu J, Li Q, Xu Q, Liu L and Jiang B: MiR-148a inhibits angiogenesis by targeting ERBB3. J Biomed Res 25: 170-177, 2011.

19. Ma MT, He M, Wang Y, Jiao XY, Zhao L, Bai XF, Yu ZJ, Wu HZ, Sun ML, Song ZG, et al: MiR-487a resensitizes mitoxantrone (MX)-resistant breast cancer cells (MCF-7/MX) to MX by targeting breast cancer resistance protein (BCRP/ABCG2). Cancer Lett 339: 107-115, 2013.

20. Bai X, Song Z, Fu Y, Yu Z, Zhao L, Zhao H, Yao W, Huang D, Mi X, Wang E, et al: Clinicopathological significance and prognostic value of DNA methyltransferase $1,3 \mathrm{a}$, and $3 \mathrm{~b}$ expressions in sporadic epithelial ovarian cancer. PLoS One 7: e40024, 2012.

21. Polakis P: Wnt signaling and cancer. Genes Dev 14: 1837-1851, 2000.

22. Karim R, Tse G, Putti T, Scolyer R and Lee S: The significance of the Wnt pathway in the pathology of human cancers. Pathology 36: 120-128, 2004.

23. Nusse R and Varmus HE: Many tumors induced by the mouse mammary tumor virus contain a provirus integrated in the same region of the host genome. Cell 31: 99-109, 1982.

24. Wong SC, Lo SF, Lee KC, Yam JW, Chan JK and Wendy Hsiao WL: Expression of frizzled-related protein and Wnt-signalling molecules in invasive human breast tumours. J Pathol 196: 145-153, 2002.

25. Wen Q, Zhao J, Bai L, Wang T, Zhang H and Ma Q: miR-126 inhibits papillary thyroid carcinoma growth by targeting LRP6. Oncol Rep 34: 2202-2210, 2015.

26. Zhang W, Shen C, Li C, Yang G, Liu H, Chen X, Zhu D, Zou H, Zhen Y, Zhang D, et al: miR-577 inhibits glioblastoma tumor growth via the Wnt signaling pathway. Mol Carcinog: Mar 12, 2015 (Epub ahead of print).

27. Subramanian M, Rao SR, Thacker P, Chatterjee $S$ and Karunagaran D: MiR-29b downregulates canonical Wnt signaling by suppressing coactivators of beta-catenin in human colorectal cancer cells. J Cell Biochem 115: 1974-1984, 2014

28. Yan H, Dong XG, Zhong XQ, Ye J, Zhou Y, Yang X, Shen J and Zhang J: Inhibitions of epithelial to mesenchymal transition and cancer stem cells-like properties are involved in miR-148a-mediated anti-metastasis of hepatocellular carcinoma. Mol Carcinog 53: 960-969, 2014

29. Joshi $P$, Jeon YJ, Laganà A, Middleton J, Secchiero $P$, Garofalo $M$ and Croce CM: MicroRNA-148a reduces tumorigenesis and increases TRAIL-induced apoptosis in NSCLC. Proc Natl Acad Sci USA 112: 8650-8655, 2015.

30. Kim J, Zhang Y, Skalski M, Hayes J, Kefas B, Schiff D, Purow B, Parsons S, Lawler S and Abounader R: microRNA-148a is a prognostic oncomiR that targets MIG6 and BIM to regulate EGFR and apoptosis in glioblastoma. Cancer Res 74, 1541-1553, 2014. 